\title{
AVALIAÇÃo SENSORIAL, MICROBIOLÓGICA E DE PÓS-ACIDIFICAÇÃO DURANTE A VIDA-DE-PRATELEIRA DE LEITES FERMENTADOS CONTENDO Streptococcus thermophilus, Bifidobacterium longum E Lactobacillus acidophilus ${ }^{1}$
}

\author{
Patrícia Blumer ZACARCHENCO ${ }^{2, *}$, Salvador MASSAGUER-ROIG ${ }^{2}$
}

\section{RESUMO}

Três leites fermentados, o primeiro por Str. thermophilus, o segundo por Bif. longum e o terceiro por Lb. acidophilus e o leite fermentado elaborado pela mistura de volumes iguais dos leites fermentados, separadamente, por Str. thermophilus, Bif. longum e Lb. acidophilus tiveram seu $\mathrm{pH}$, acidez titulável, atributos sensoriais de sabor e acidez, e contagens de células viáveis determinadas, ao longo de 21 dias de estocagem a $4^{\circ} \mathrm{C}$. Não houve diferença significativa $(\mathrm{p}<0,05)$ para os atributos sensoriais entre o leite fermentado elaborado por mistura e aquele contendo apenas Str. thermophilus. O leite fermentado por Str. thermophilus apresentou a maior acidez e menor pH, enquanto o leite fermentado por Bif. longum apresentou a menor acidez e maior pH. As populaçōes de Str. thermophilus e Bif. longum mantiveram-se constantes até 21 dias de estocagem, tanto nos leites fermentados isoladamente como no leite elaborado pela mistura, enquanto as populações de $L b$. acidophilus apresentaram redução de um ciclo logarítmico.

Palavras-chave: Bifidobacterium; Lactobacillus acidophilus; leite fermentado; características sensoriais; bebida láctea

\section{SUMMARY}

MICROBIOLOGICAL, SENSORY AND POST-ACIDIFICATION EVALUATION DURING SHELF-LIFE OF FERMENTED MILKS CONTAINING Streptococcus thermophilus, Bifidobacterium longum AND Lactobacillus acidophilus. Taste and acidity sensorial attributes, $\mathrm{pH}$, titratable acidity and microbial counts of milks fermented separately by Bifidobacterium longum, Lactobacillus acidophilus and Streptococcus thermophilus and a beverage prepared by mixing them were studied during 21 days at $4^{\circ} \mathrm{C}$. The mixed beverage and Str. thermophilus fermented milk did not differ significantly $(\mathrm{p}<0.05)$ for the sensorial attributes among them. Milk fermented by Str. thermophilus showed the highest titratable acidity and the lowest $\mathrm{pH}$ while milk fermented by Bif. longum showed the lowest titratable acidity and the highest pH. Str. thermophilus and Bif. longum counts remained constant in the beverage and in the separated fermented milks, during the 21 days of storage, while $L b$. acidophilus counts were reduced by 1 log cycle.

Keywords: Bifidobacterium; Lactobacillus acidophilus; fermented milk; sensory properties; milk beverage;

\section{1 - INTRODUÇÃO}

O uso de Bifidobacterium spp. e/ou Lactobacillus acidophilus em leites fermentados tornou-se popular no final da década de 70, como resultado dos avanços científicos na área de taxonomia e ecologia das bifidobactérias. Sua popularidade também aumentou devido a sua característica de baixa capacidade de acidificação durante a estocagem. Muitas patentes surgiram principalmente devido aos desenvolvimentos ocorridos na produção de fermentos e de novos produtos [7].

VINDEROLA, BAILO \& REINHEIMER [21] afirmaram que a adição de bactérias probióticas ao leite fermentado é prática amplamente adotada pelos laticínios. Contudo, fatores como acidez do iogurte, oxigênio dissolvido, interações entre espécies, práticas de inoculação e condições de estocagem podem condicionar a sobrevivência da microbiota probiótica em produtos lácteos fermentados [20, 21]. Sobre condições de estocagem destes produtos, os mesmos autores [21] concluíram não haver estudos suficientes sobre a sobrevivência dos probióticos durante a estocagem refrigerada.

1. Recebido para publicação em 10/11/2003. Aceito para publicação em 14/10/2004 (001245).

2. Departamento de Tecnologia de Alimentos, Faculdade de Engenharia de Alimentos, Universidade Estadual de Campinas. Cx. P. 6121, CEP 13083-970, Campinas, S.P., Brasil. E-mail: patylene@hotmail.com * A quem a correspondência deve ser enviada.
As bifidobactérias são usadas em fermentações de leite de modo limitado devido ao lento crescimento. Embora o leite seja um meio satisfatório por conter nutrientes essenciais, aminoácidos e pequenos peptídios estão presentes em quantidades insuficientes para o crescimento de bifidobactérias. Há, contudo, relatos de casos de adaptação das bifidobactérias ao leite após sucessivas transferências [7].

De acordo com KLAVER, KINGMA \& WEERKAMP [8] as bactérias probióticas se desenvolvem lentamente no leite devido a sua baixa atividade proteolítica, sendo prática comum a adição de bactérias do iogurte para reduzir o tempo de fermentação. Contudo, Lactobacillus delbrueckii spp. bulgaricus, uma das bactérias do iogurte, produz ácido lático durante a estocagem refrigerada (pós-acidificação) o que afeta, segundo estes autores, a viabilidade das bactérias probióticas. A fim de superar o problema da pós-acidificação, de acordo com DAVE \& SHAH [4], a atual tendência é usar fermentos chamados ABT, que contém $L b$. acidophilus, bifidobactéria e Str. thermophilus. Também OLIVEIRA et al. [16] afirmaram que bactérias láticas podem ser adicionadas durante a mistura final do produto diminuindo os custos da produção de leite fermentado contendo probióticos.

Em geral, bifidobactérias se desenvolvem melhor em meios sintéticos do que em leite. Contudo, estes meios são caros para multiplicação de bifidobatérias em grande escala, além de causarem sabores desagradáveis nos produtos finais. Assim, melhora das condi- 
ções de multiplicação para diferentes linhagens de bifidobactérias no leite, por exemplo, pela adição de fontes de nitrogênio ou substâncias que abaixem o potencial redox do meio e a seleção de linhagens menos fastidiosas são alternativas propostas para superar esses problemas [7]. De acordo com MATTILASANDHOLM, MÄTTÖ \& SAARELA [14] a seleção cuidadosa das linhagens empregadas e o monitoramento do processo de fabricação são necessários para controlar os produtos de metabolismo e o pH final.

VINDEROLA et al. [20,21] relataram que o sucesso da adição de culturas probióticas é dependente das espécies e linhagens usadas, das interações metabólicas com bactérias láticas, das condições de fermentação, do $\mathrm{pH}$ do produto, da presença de oxigênio e da temperatura de estocagem. Outros autores [14] citam ainda a resistência a fagos e viabilidade durante o processamento e estocagem.

Como as bifidobactérias produzem, durante a fermentação, ácidos acético [17] e lático a taxa de 3:2, seu desenvolvimento excessivo pode gerar produtos com sabor e aroma "a vinagre", dificultando a aceitação do produto pelos consumidores. Assim, uma combinação de linhagens específicas deve ser determinada para evitar esse problema, selecionando-se aquelas que promovam as propriedades sensoriais e de sobrevivência mais vantajosas [13].

De acordo com GOMES \& MALCATA [7], em função da baixa velocidade de multiplicação das culturas probióticas em relação às bactérias láticas tradicionais, controle da assepsia e adição de fatores promotores de crescimento são pré-requisitos para se obter altas contagens iniciais de células viáveis de probióticos. Caso contrário, esta população ficaria muito abaixo daquela do fermento.

GOMES \& MALCATA [7] enfatizaram que os fabricantes devem observar se os bio-produtos fermentados contêm número mínimo satisfatório de células ativas no momento do consumo de, pelo menos, $10^{6} \mathrm{UFC} / \mathrm{mL}$ devido a dose mínima terapêutica diária ser de $10^{8}-10^{9}$ células viáveis em $100 \mathrm{~g}$ do bio-produto fermentado. Outros autores [18] sugerem que para efeito terapêutico o produto deve conter $\geq 10^{5}$ células $/ \mathrm{mL}$. A legislação brasileira fixa o limite mínimo em $10^{6} \mathrm{UFC} / \mathrm{mL}$ [3].

Os objetivos deste trabalho foram comparar uma bebida láctea contendo Lb. acidophilus, Bif. longum e Str. thermophilus, elaborada pela mistura de leites fermentados em separado por estes microrganismos, com leites fermentados por cada um destes microrganismos, quanto aos seus atributos sensoriais de sabor e acidez, pH, acidez titulável e populações microbianas ao longo de 21 dias de estocagem a $4^{\circ} \mathrm{C}$.

\section{2 - MATERIAIS E MÉTODOS}

\section{1 - Materiais}

Triptona, bacto bile, bacto peptona, ágar (Difco, Detroit, Mi, USA); sacarose, extrato de levedura, púr- pura de bromo-cresol (Merck, Darmstadt, Ge); $\mathrm{KH}_{2} \mathrm{PO} 4$, propionato de sódio (SIGMA, St. Louis, MO, USA); cloreto de lítio (Synth, Diadema, SP, Brasil); Anaerobac (Probac, São Paulo, SP, Brasil); ágar MRS (Oxoid, Basingstoke, Hampshire, En); leite em pó desnatado (Molico, Nestlé, Araçatuba, SP, Brasil). Leite desnatado UAT (SHEFA, Amparo, SP, Brasil). Culturas liofilizadas de Str. thermophilus, TA 559 (STr), Lb. acidophilus, LAC4 (LAC) e Bif. longum, BL (BL) da Ezal ${ }^{\circledR}$ - Texel fornecidos por Rhodia Food.

\section{2 - Métodos}

\subsection{1 - Preparação dos inóculos para os leites fermentados}

Leite desnatado reconstituído a $11 \%$ foi utilizado para o preparo dos fermentos de Str. thermophilus (STr). Para o fermento de $\mathrm{Lb}$. acidophilus (LAC) utilizou-se leite reconstituído a $11 \%$ adicionado de $0,5 \%$ de extrato de levedura, enquanto para o fermento de Bif. longum (BL) esta mistura foi também enriquecida com $0,05 \%$ de cisteína. Todos os leites reconstituídos foram esterilizados a $115^{\circ} \mathrm{C} / 10 \mathrm{~min}$ e a solução de cisteína utilizada foi esterilizada por filtração. Todas as etapas de manipulação dos microrganismos foram realizadas em câmara de fluxo laminar.

\subsection{2 - Obtenção do leite fermentado por Str. thermophilus}

Leite desnatado reconstituído a $12 \%$ de sólidos totais foi tratado a $95^{\circ} \mathrm{C}$ por 5 minutos, resfriado a $43^{\circ} \mathrm{C}$ e inoculado com $2 \%$ de fermento de Str. thermophilus. Após 3h de fermentação, o leite fermentado foi resfriado a $20^{\circ} \mathrm{C}$ para batimento. Este leite fermentado foi codificado por $\mathrm{C} 1$.

Para a bebida láctea probiótica, leite desnatado reconstituído a $20 \%$ de sólidos totais foi tratado a $95^{\circ} \mathrm{C}$ por 5 minutos, resfriado a $43^{\circ} \mathrm{C}$, inoculado com $2 \%$ de fermento de Str. thermophilus, fermentado a $43^{\circ} \mathrm{C}$ em aproximadamente 3,5 horas e resfriado a $20^{\circ} \mathrm{C}$ para batimento.

\subsection{3 - Obtenção dos leites fermentados por $L b$. acidophilus e Bif. longum}

Embalagens de leite UAT desnatado foram, assepticamente, abertas e o leite acondicionado em recipientes estéreis. Ajustou-se a temperatura do leite para $37^{\circ} \mathrm{C}$, e inoculou-se com $4 \%$ de fermento constituído por Bif. longum. A fermentação foi realizada a $37^{\circ} \mathrm{C}$ por 20 a 22 horas, e estes leites foram codificados por C2. Procedeu-se do mesmo modo para elaboração dos leites fermentados por $\mathrm{Lb}$. acidophilus tendo-se usado $2 \%$ de inóculo, fermentação a $37^{\circ} \mathrm{C}$ por 16 a 18 horas. Este leite fermentado foi codificado por C3.

\subsection{4 - Elaboração da bebida láctea probiótica}

A bebida láctea probiótica foi elaborada pela mistura de 1000 g de leite fermentado por Str.thermophilus a 
$20 \%$ de sólidos, 1000 g de leite fermentado por $L b$. acidophilus e $1000 \mathrm{~g}$ de leite fermentado por Bif. longum. A mistura obtida foi batida por 2 minutos em batedeira planetária, previamente higienizada, (marca Walita). Esta bebida foi codificada por C4.

\subsection{5 - Embalagem e estocagem da bebida láctea e dos leites fermentados}

Após o batimento, as formulações foram envasadas em garrafas de vidro esterilizadas, sendo, então, estocadas em câmara fria, a $4^{\circ} \mathrm{C}$. Foram realizados dois processamentos, referidos neste texto como processamentos 1 e 2 .

\subsection{6 - Vida-de-prateleira dos leites fermenta- dos}

Os leites fermentados foram avaliados nos dias 1, 7, 14 e 21 quanto a pH, acidez titulável, avaliação sensorial dos atributos de sabor e acidez, e determinação de células viáveis de Str. thermophilus, $L b$. acidophilus e Bif. longum.

\subsection{7 - Determinações de pH e de acidez}

$\mathrm{O}$ pH foi determinado utilizando o potenciômetro pH320 da marca WTW. A acidez titulável foi determinada de acordo com a metodologia da AOAC [1], em triplicata.

\subsection{8 - Quantificações dos microrganismos}

O ágar ST (ágar Streptococcus thermophilus) foi preparado de acordo com DAVE \& SHAH [5], mas incubado em aerobiose a $30^{\circ} \mathrm{C}$ por $48 \mathrm{~h}$ de acordo com ZACARCHENCO \& MASSAGUER-ROIG [23]. O ágar Bile-MRS foi preparado de acordo com VINDEROLA \& REINHEIMER [22], e incubado a $37^{\circ} \mathrm{C}$ por $72 \mathrm{~h}$ em aerobiose. O ágar Cloreto de Lítio - Propionato de Sódio (LP-MRS) foi preparado de acordo com LAPIERRE, UNDELAND \& COX [9], usando o meio base sugerido em VINDEROLA \& REINHEIMER [22], sendo as concentrações de agentes inibitórios $0,5 \mathrm{~g} / \mathrm{L}$ de $\mathrm{LiCl}$ e $0,75 \mathrm{~g} / \mathrm{L}$ de propionato de sódio, de acordo com ZACARCHENCO \& MASSAGUER-ROIG [24], e incubado a $37^{\circ} \mathrm{C}$ por $72 \mathrm{~h}$ em anaerobiose. Os plaqueamentos foram realizados em duplicata.

\subsection{9 - Análise sensorial}

A avaliação dos atributos sensoriais de sabor e acidez de cada produto, nos dois processamentos, foi realizada utilizando-se equipe de provadores composta por 35 consumidores potenciais dos produtos, selecionados em função da disponibilidade, interesse e hábito de consumir bebidas lácteas sem adição de açúcar.

As análises sensoriais foram realizadas em amostras $(25 \mathrm{~g})$ servidas a $7^{\circ} \mathrm{C}$, codificadas e apresentadas aos provadores em seqüências aleatorizadas de acordo com MACFIE et al. [12]. Os testes de aceitação foram realizados usando escala hedônica estruturada mista de 9 pontos ( 1 = desgostei muitíssimo; $5=$ nem gostei, nem desgostei; 9 = gostei muitíssimo) de acordo com MEILGAARD, CIVILLE \& CARR [15].

\subsubsection{0 - Análise estatística}

Os resultados dos testes de aceitação foram avaliados através de Análise de Variância e teste de Tukey, usando o programa "Statistical Analysis System" (SAS 8.02 TS level 02M0). O valor de $\mathrm{P}<0.05$ foi considerado como significante.

\section{3 - RESULTADOS E DISCUSSÃO}

Os resultados das medidas de $\mathrm{pH}$, acidez titulável, contagem de células viáveis e médias das notas obtidas nos testes de aceitação dos leites fermentados, durante a estocagem nos dias $1,7,14$ e 21 estão apresentados nas Tabelas 1, 2, 3 e 4 .

TABELA 1. Valores de $\mathrm{pH}$, acidez, contagens microbianas e médias das notas obtidas nos testes de preferência das formulações de leite fermentado por Str. thermophilus (C1), leite fermentado por Bif. longum (C2), leite fermentado por Lac. acidophilus (C3) e na bebida obtida pela mistura destes 3 leites fermentados (C4) medidas no dia 1 de estocagem a $4^{\circ} \mathrm{C}$ nos processamentos 1 e 2 .

\begin{tabular}{ccccccccc}
\hline Proc. & Comb. & $\mathrm{pH}$ & Acid Tit $^{\mathrm{N}}$ & STr $^{\mathrm{II}}$ & LAC $^{\mathrm{II}}$ & $\mathrm{BL}^{\mathrm{N}}$ & sabor $^{\mathrm{V}}$ & acidez $^{\mathrm{V}}$ \\
\hline 1 & $\mathrm{C} 1$ & 4.44 & 107.7 & $1.8 \times 10^{9}$ & - & - & $5.8^{\mathrm{a}}$ & $6.0^{\mathrm{ab}}$ \\
1 & $\mathrm{C} 2$ & 5.11 & 64.5 & - & - & $4.7 \times 10^{8}$ & $4.5^{\mathrm{b}}$ & $5.6^{\mathrm{b}}$ \\
1 & $\mathrm{C} 3$ & 4.68 & 77.2 & - & $7.4 \times 10^{8}$ & - & $5.9^{\mathrm{a}}$ & $6.6^{\mathrm{ab}}$ \\
1 & $\mathrm{C} 4$ & 4.86 & 95.7 & $4.9 \times 10^{8}$ & $1.3 \times 10^{8}$ & $2.6 \times 10^{8}$ & $6.5^{\mathrm{a}}$ & $6.7^{\mathrm{a}}$ \\
2 & $\mathrm{C} 1$ & 4.47 & 109.7 & $1.3 \times 10^{9}$ & - & - & $6.3^{\mathrm{a}}$ & $6.6^{\mathrm{ab}}$ \\
2 & $\mathrm{C} 2$ & 5.0 & 73.7 & - & - & $1.5 \times 10^{9}$ & $1.9^{\mathrm{c}}$ & $4.0^{\mathrm{c}}$ \\
2 & $\mathrm{C} 3$ & 4.78 & 70.3 & - & $2.4 \times 10^{8}$ & - & $4.6^{\mathrm{b}}$ & $5.3^{\mathrm{bc}}$ \\
2 & $\mathrm{C} 4$ & 4.88 & 96.0 & $7.4 \times 10^{8}$ & $2.0 \times 10^{8}$ & $4.0 \times 10^{8}$ & $6.4^{\mathrm{a}}$ & $6.7^{\mathrm{a}}$ \\
\hline
\end{tabular}

I. Acid Tit significa acidez titulável:

II, III e IV. STr, LAC e BL significa Str. thermophilus, Lb. acidophilus e Bif. longum,

respectivamente;
$\mathrm{V}$ - Letras diferentes indicam diferenças significativas $(\mathrm{P}<0.05)$ entre as combinações de leites fermentados.

TABELA 2. Valores de $\mathrm{pH}$, acidez, contagens microbianas e médias das notas obtidas nos testes de preferência das formulações de leite fermentado por Str. thermophilus (C1), leite fermentado por Bif. longum (C2), leite fermentado por Lac. acidophilus (C3) e na bebida obtida pela mistura destes 3 leites fermentados (C4) medidas no dia 7 de estocagem a $4^{\circ} \mathrm{C}$ nos processamentos 1 e 2

\begin{tabular}{ccccccccc}
\hline Proc. & Comb. & $\mathrm{pH}$ & Acid Tit $^{\prime}$ & STr $^{\prime \prime}$ & LAC $^{\prime \prime}$ & BL $^{\mathrm{V}}$ & sabor $^{\mathrm{V}}$ & acidez $^{\mathrm{V}}$ \\
\hline 1 & $\mathrm{C} 1$ & 4.3 & 114.2 & $3.7 \times 10^{9}$ & - & - & $5.0^{\mathrm{a}}$ & $5.6^{\mathrm{ab}}$ \\
1 & $\mathrm{C} 2$ & 5.12 & 64.6 & - & - & $3.9 \times 10^{8}$ & $4.0^{\mathrm{b}}$ & $4.9^{\mathrm{b}}$ \\
1 & $\mathrm{C} 3$ & 4.7 & 77.2 & - & $6.2 \times 10^{8}$ & - & $5.7^{\mathrm{a}}$ & $6.0^{\mathrm{a}}$ \\
1 & $\mathrm{C} 4$ & 4.69 & 114.5 & $1.1 \times 10^{9}$ & $2.1 \times 10^{8}$ & $2.7 \times 10^{8}$ & $6.4^{\mathrm{a}}$ & $6.2^{\mathrm{a}}$ \\
2 & $\mathrm{C} 1$ & 4.34 & 116.1 & $2.2 \times 10^{9}$ & - & - & $6.7^{\mathrm{a}}$ & $6.6^{\mathrm{a}}$ \\
2 & C2 & 4.99 & 74.8 & - & - & $8.5 \times 10^{8}$ & $2.8^{\mathrm{c}}$ & $4.2^{\mathrm{b}}$ \\
2 & $\mathrm{C} 3$ & 4.81 & 76.5 & - & $2.7 \times 10^{8}$ & - & $4.9^{\mathrm{b}}$ & $5.4^{\mathrm{ab}}$ \\
2 & $\mathrm{C} 4$ & 4.69 & 110.0 & $6.3 \times 10^{8}$ & $1.1 \times 10^{8}$ & $2.7 \times 10^{8}$ & $5.2^{\mathrm{ab}}$ & $5.5^{\mathrm{ab}}$
\end{tabular}

I. Acid Tit significa acidez titulável;
II, III e IV. STr, LAC e BL significa Str. thermophilus, Lb. acidophilus e Bif. longum,

respectivamente; de leites fermentados. 
TABELA 3. Valores de $\mathrm{pH}$, acidez, contagens microbianas e médias das notas obtidas nos testes de preferência das formulações de leite fermentado por Str. thermophilus (C1), leite fermentado por Bif. longum (C2), leite fermentado por Lac. acidophilus (C3) e na bebida obtida pela mistura destes 3 leites fermentados (C4) medidas no dia 14 de estocagem a $4^{\circ} \mathrm{C}$ nos processamentos 1 e 2 .

\begin{tabular}{ccccccccc}
\hline Proc. & Comb. & pH & Acid Tit $^{\prime}$ & STr $^{\prime \prime}$ & LAC $^{\text {III }}$ & BL $^{\mathrm{N}}$ & sabor $^{\mathrm{V}}$ & acidez $^{\mathrm{V}}$ \\
\hline 1 & $\mathrm{C} 1$ & 4.27 & 129.6 & $1.2 \times 10^{9}$ & - & - & $6.5^{\mathrm{a}}$ & $6.0^{\mathrm{a}}$ \\
1 & $\mathrm{C} 2$ & 5.12 & 66.9 & - & - & $3.0 \times 10^{8}$ & $3.5^{\mathrm{c}}$ & $4.6^{\mathrm{b}}$ \\
1 & $\mathrm{C} 3$ & 4.6 & 80.6 & - & $3.1 \times 10^{8}$ & - & $5.3^{\mathrm{b}}$ & $5.7^{\mathrm{ab}}$ \\
1 & $\mathrm{C} 4$ & 4.56 & 123.5 & $1.1 \times 10^{8}$ & $2.4 \times 10^{8}$ & $2.3 \times 10^{8}$ & $5.5^{\mathrm{ab}}$ & $5.6^{\mathrm{ab}}$ \\
2 & $\mathrm{C} 1$ & 4.24 & 127.8 & $1.3 \times 10^{9}$ & - & - & $6.4^{\mathrm{a}}$ & $6.5^{\mathrm{a}}$ \\
2 & $\mathrm{C} 2$ & 4.98 & 73.0 & - & - & $9.4 \times 10^{8}$ & $2.6^{\mathrm{c}}$ & $4.1^{\mathrm{b}}$ \\
2 & $\mathrm{C} 3$ & 4.79 & 77.3 & - & $1.1 \times 10^{8}$ & - & $4.7^{\mathrm{b}}$ & $5.4^{\mathrm{ab}}$ \\
2 & $\mathrm{C} 4$ & 4.56 & 116.6 & $6.2 \times 10^{8}$ & $7.4 \times 10^{7}$ & $2.3 \times 10^{8}$ & $6.2^{\mathrm{a}}$ & $5.3^{\mathrm{ab}}$ \\
\hline
\end{tabular}

I. Acid Tit significa acidez titulável;

II, III e IV. STr, LAC e BL significa Str. thermophilus, Lb. acidophilus e Bif. longum, respectivamente;

$\mathrm{V}$ - Letras diferentes indicam diferenças significativas $(\mathrm{P}<0.05)$ entre as combinações de leites fermentados.

TABELA 4. Valores de $\mathrm{pH}$, acidez, contagens microbianas e médias das notas obtidas nos testes de preferência das formulações de leite fermentado por Str. thermophilus (C1), leite fermentado por Bif. longum (C2), leite fermentado por Lac. acidophilus (C3) e na bebida obtida pela mistura destes 3 leites fermentados (C4) medidas no dia 21 de estocagem a $4^{\circ} \mathrm{C}$ nos processamentos 1 e 2 .

\begin{tabular}{ccccccccc}
\hline Proc. & Comb. & $\mathrm{pH}$ & Acid Tit $^{1}$ & STr $^{\mathrm{II}}$ & $\mathrm{LAC}^{\mathrm{II}}$ & BL $^{\mathrm{IV}}$ & sabor $^{\mathrm{V}}$ & acidez $^{\mathrm{V}}$ \\
\hline 1 & $\mathrm{C} 1$ & 4.19 & 135.5 & $1.4 \times 10^{9}$ & - & - & $5.8^{\mathrm{a}}$ & $6.1^{\mathrm{ab}}$ \\
1 & $\mathrm{C} 2$ & 5.06 & 70.3 & - & - & $4.9 \times 10^{8}$ & $4.2^{\mathrm{b}}$ & $5.3^{\mathrm{b}}$ \\
1 & $\mathrm{C} 3$ & 4.63 & 78.9 & - & $2.1 \times 10^{8}$ & - & $6.0^{\mathrm{a}}$ & $6.4^{\mathrm{ab}}$ \\
1 & $\mathrm{C} 4$ & 4.5 & 121.7 & $8.2 \times 10^{8}$ & $4.0 \times 10^{7}$ & $2.7 \times 10^{8}$ & $6.1^{\mathrm{a}}$ & $6.5^{\mathrm{a}}$ \\
2 & $\mathrm{C} 1$ & 4.20 & 129.5 & $1.5 \times 10^{9}$ & - & - & $6.6^{\mathrm{a}}$ & $6.2^{\mathrm{a}}$ \\
2 & $\mathrm{C} 2$ & 4.96 & 78.0 & - & - & $6.9 \times 10^{8}$ & $2.6^{\mathrm{c}}$ & $4.6^{\mathrm{b}}$ \\
2 & $\mathrm{C} 3$ & 4.78 & 85.7 & - & $1.2 \times 10^{8}$ & - & $5.5^{\mathrm{b}}$ & $5.7^{\mathrm{ab}}$ \\
2 & $\mathrm{C} 4$ & 4.53 & 119.7 & $4.8 \times 10^{8}$ & $3.7 \times 10^{7}$ & $2.3 \times 10^{8}$ & $5.9^{\mathrm{ab}}$ & $6.4^{\mathrm{a}}$
\end{tabular}

I. Acid Tit significa acidez titulável;

II, III e IV. STr, LAC e BL significa Str. thermophilus, Lb. acidophilus e Bif. longum, respectivamente;

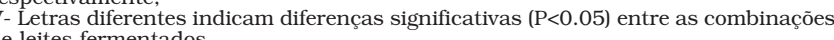

\section{1 - Análise sensorial do atributo sabor}

Em todas as análises sensoriais para sabor $(1,7$, 14 e 21 dias) em ambos os processamentos, C1 e C4 não diferiram entre si $(\mathrm{P}<0,05)$ (Tabelas 1 a 4). Apesar de relatos de produção de ácido acético [11, 19] por bifidobactérias, que confeririam sabor e aroma "a vinagre” ao produto de fermentação, este defeito não foi detectado na bebida láctea $\mathrm{C} 4$, que contém Bif. longum.

Painéis sensoriais comparando sorvetes de iogurte contendo Bifidobacterium com os sorvetes de iogurte tradicionais, nos estudos de DAVIDSON et al. [6], não apontaram diferenças entre os produtos. Também neste estudo, o leite fermentado produzido pela mistura de leites fermentados contendo probióticos (C4) não diferiu do tradicional $(\mathrm{C} 1)$ no atributo sabor. De maneira similar ZACARCHENCO [25] encontrou diferença entre leite fermentado por STr adicionado de populações iguais de BL e LAC $\left(10^{8} \mathrm{UFC} / \mathrm{mL}\right)$ e leite fermenta- do apenas por STr, ao longo de 21 dias de estocagem refrigerada, da mesma forma que no presente trabalho.

Em todas as análises sensoriais para sabor $(1,7$, 14 e 21 dias) $\mathrm{C} 1$ e $\mathrm{C} 4$ diferiram, significativamente, de C2. No 7ํ dia, C3 apresentou avaliação sensorial estatisticamente igual a $\mathrm{C} 4$ (processamentos 1 e 2) e C1 (processamento 1). No $14^{\circ}$ dia, C3 mostrou-se estatisticamente igual a $\mathrm{C} 4$ apenas no processamento 1. Após 21 dias de estocagem a $4^{\circ} \mathrm{C}, \mathrm{C} 3$ apresentou avaliação sensorial estatisticamente igual a $\mathrm{C} 4$ (processamentos 1 e 2) e $\mathrm{Cl}$ (processamento 1).

\section{2 - Análise sensorial do atributo acidez}

Após um dia de estocagem a $4^{\circ} \mathrm{C}$, a bebida láctea C4 obteve maior pontuação média, entre os provadores, para o atributo acidez não diferindo, significativamente $(\mathrm{p}<0,05)$, de $\mathrm{C} 1$ em ambos processamentos ( $\mathrm{Ta}$ belas 1 a 4 ).

Quanto ao atributo acidez, ZACARCHENCO [25] encontrou que leites fermentados por STr adicionados de populações iguais de BL (Bif. longum) e LAC ( $L b$. acidophilus) $\left(10^{8} \mathrm{UFC} / \mathrm{mL}\right)$ na forma liofilizada não apresentaram acidez diferentes do leite fermentado apenas por STr ao longo de 21 dias de estocagem refrigerada.

Nas análises sensoriais realizadas no $1^{\circ}$ dia de estocagem, C4 diferiu significativamente de C2, enquanto C3 apresentou avaliação sensorial estatisticamente igual a C4 (processamento 1) e C1 (processamentos 1 e 2) (Tabelas 1 a 4). Nos dias 7, 14 e 21 de estocagem, C4, $\mathrm{C} 1$ e C3 não diferiram entre si $(\mathrm{P}<0,05)$. No $7^{\circ}$ dia, $\mathrm{C} 2$ diferiu de $\mathrm{C} 4$ (processamento 1) e de $\mathrm{C} 1$ (processamento 2). Já no $14^{\circ}$ dia, C2 foi significativamente diferente apenas de $\mathrm{C} 1$. No $21^{\circ}$ dia de estocagem, $\mathrm{C} 2$ diferiu de $\mathrm{C} 4$ (processamentos 1 e 2) e C1 (processamento 2).

\section{3 - Medidas de pH e acidez titulável dos leites fermentados}

Os menores valores de $\mathrm{pH}$ e os maiores de acidez titulável foram encontrados no leite fermentado $\mathrm{C} 1$. Por sua vez, os maiores valores de $\mathrm{pH}$ e os menores de acidez titulável foram encontrados no leite fermentado C2. Estas observações puderam ser verificadas durante todo o período de estocagem, nos 2 processamentos (Tabelas 1 a 4). Os valores de pH de C2 são coerentes com a observação de GOMES \& MALCATA [7] acerca do pH após fermentação de leites por bifidobactérias. Também MATTILA-SANDHOLM et al. [13] afirmaram que a capacidade de produção de ácidos orgânicos pelas bifidobactérias em leite é limitada, o que explica os maiores valores de $\mathrm{pH}$ de $\mathrm{C} 2$ em relação aos outros leites fermentados.

OLIVEIRA et al. [16] consideraram que variações de $\mathrm{pH}$, ao longo do tempo de estocagem, menores que 0,12 são decréscimos menores e, variações entre 0,14 e 0,32, decréscimos perceptíveis. Assim, de acordo com OLIVEIRA et al. [16], C1 (variações de 0,25 a 0,27) e C4 (variações de 0,35 a 0,36) apresentaram decréscimos perceptiveis de $\mathrm{pH}$, enquanto $\mathrm{C} 2(0,04-0,05)$ e C3 $(0,05)$ 
apresentaram decréscimos menores. Os valores de $\mathrm{pH}$ obtidos para C2 e C3 estão de acordo com as afirmações de DAVE \& SHAH $[4,5]$ sobre a reduzida capacidade de acidificação destes microrganismos na estocagem refrigerada.

Contudo os valores maiores de $\mathrm{pH}$ em $\mathrm{C} 4$, quando comparados aos de C1 (Tabelas 1 a 4), também concordaram com os relatos de GOMES \& MALCATA [7] sobre a inibição da acidificação de produtos lácteos fermentados contendo probióticos, durante a estocagem refrigerada

SHAH et al. [18] analisando iogurtes comerciais contendo LAC e Bif bifidum encontraram valores de $\mathrm{pH}$, logo após o resfriamento que segue a fermentação, entre 4,07 e 4,36. Após 33 dias de estocagem esses valores de $\mathrm{pH}$ baixaram para 3,8 a 4,26, respectivamente.

\section{4 - Contagens de células viáveis nos leites fer- mentados}

Os leites fermentados C1 e C4 apresentaram contagens de células viáveis de Str. thermophilus constantes ao longo dos 21 dias de estocagem refrigerada, respectivamente ao redor de $10^{8} \mathrm{UFC} / \mathrm{mL}$ e $10^{9} \mathrm{UFC} / \mathrm{mL}$. Esta diferença foi decorrente da diluição do leite fermentado por STr para elaboração da bebida láctea. Também, devido a este efeito, nota-se valores de contagens de células viáveis de LAC e BL menores na bebida láctea que em C2 e C3. Os valores das contagens para STr variaram entre 1,2 e $3,7 \times 10^{9} \mathrm{UFC} / \mathrm{mL}$ (Tabelas 1 a 4). OLIVEIRA et al. [16] relataram que STr predominou em todos os produtos onde estava presente.

As contagens de células viáveis de LAC em C3 e C4 apresentaram uma redução de $10^{8} \mathrm{UFC} / \mathrm{mL}$ para $10^{7} \mathrm{UFC} / \mathrm{mL}$ após 21 dias de estocagem (Tabelas 1 a 4), a qual foi observada a partir do $14^{\circ} \circ$ dia em C4 no $2^{\circ}$ processamento. OLIVEIRA et al. [16] relataram a redução de 2 ciclos logarítmicos nas contagens de LAC após 28 dias de estocagem a $4^{\circ} \mathrm{C}$, na presença de STr. Estes autores relataram também decréscimos acima de 1 ciclo logarítmico para LAC em fermentações apenas com este microrganismo. Os resultados de BOZANIC, ROGELI \& TRATNIK [2], que elaboraram leites fermentados por LAC mostraram contagens superiores a $10^{6} \mathrm{UFC} / \mathrm{mL}$.

Não houve reduções consideráveis nas populações de $\mathrm{BL}$ em $\mathrm{C} 2$ e $\mathrm{C} 4$ visto que as contagens mantiveramse ao redor de $10^{8} \mathrm{UFC} / \mathrm{mL}$. LANKAPUTHRA, SHAH \& BRITZ [11] realizaram estudos de sobrevivência, sob condições de acidez nos pH 3,7, 3,9, 4,1 e 4,3, com 9 linhagens de bifidobactérias. No estudo destes pesquisadores, após 24 dias de estocagem a $4^{\circ} \mathrm{C}$, uma das linhagens de Bif. longum e uma de Bif. pseudolongum apresentavam contagens ao redor de $10^{8} \mathrm{UFC} / \mathrm{mL}$, mesmo valor obtido no final do processamento, antes da estocagem refrigerada.

O leite fermentado $\mathrm{C} 4$, que apresentou a maior variação de $\mathrm{pH}$ (Tabelas 1 a 4), mostrou contagens mínimas aceitáveis de células viáveis de BL e LAC, mantendo-se acima de $10^{6} \mathrm{UFC} / \mathrm{mL}$ após 21 dias de estocagem. LOURENS-HATTINGH \& VILJOEN [10] relataram que em pH 4,0 o número de células viáveis de LAC não decresceu significativamente. Contudo, há trabalhos que apontam perda de viabilidade de LAC nesta faixa de $\mathrm{pH}$ o que poderia ser, portanto, dependente da linhagem. LOURENS-HATTINGH \& VILJOEN [10] também afirmaram que a tolerância a acidez de Bifidobacterium spp. depende da linhagem. Segundo TAMIME, MARSHALL \& ROBINSON [19] a maioria das linhagens de bifidobactérias é sensivel a pH menores que 4,6. Contudo, LANKAPUTHRA, SHAH \& BRITZ [11] concluíram que Bif. longum e Bif. pseudolongum sobrevivem melhor em condições de acidez que outras linhagens de bifidobactérias estudadas.

ZACARCHENCO [25] relatou que as contagens de LAC e BL reduziram-se em 2 ciclos logarítmicos ao final da estocagem. Contudo, no presente trabalho esta redução não foi observada com BL, as contagens mantiveram-se constantes ao longo da estocagem refrigerada mesmo com a diluição efetuada para a elaboração da bebida láctea $\mathrm{C} 4$. LAC, porém, apresentou reduções de 1 ciclo logarítmico ao final da estocagem de C2 e C4.

VINDEROLA et al. [22] concluíram que LAC é mais sensivel que bifidobactérias nos meios ácidos estudados (iogurtes e leite acidificado com ácido lático) na faixa de $\mathrm{pH}$ de 3,5 to 4,5 .

\section{4 - CONCLUSÕES}

O leite fermentado por Str. thermophilus (C1) e a bebida láctea (C4) elaborada pela mistura de volumes iguais de leites fermentados em separado por Str. thermophilus, Bif. longum e Lb. acidophilus não diferiram entre si $(\mathrm{P}<0,05)$ para os atributos sabor e acidez durante a estocagem refrigerada.

Os menores valores de $\mathrm{pH}$ e os maiores de acidez titulável foram encontrados no leite fermentado apenas por Str. thermophilus, enquanto o leite fermentado por Bif. longum apresentou a menor acidez titulável e maior $\mathrm{pH}$.

A bebida láctea, que apresentou o maior abaixamento de $\mathrm{pH}$, manteve valores mínimos aceitáveis para Bif. longum e Lb. acidophilus (acima de $10^{6} \mathrm{UFC} / \mathrm{mL}$ após 21 dias de estocagem).

O leite fermentado apenas por Str. thermophilus e a bebida láctea elaborada pela mistura de volumes iguais de leites fermentados em separado, apresentaram contagens constantes de Str. thermophilus ao longo dos 21 dias de estocagem refrigerada. Também o leite fermentado por Bif. longum e a bebida láctea apresentaram contagens constantes de Bif. longum.

As contagens de $L b$. acidophilus no leite fermentado por este microrganismo e na bebida láctea reduziram de $10^{8} \mathrm{UFC} / \mathrm{mL}$ para $10^{7} \mathrm{UFC} / \mathrm{mL}$ após 21 dias de estocagem, enquanto que para Bif. longum, mantiveramse constantes, ao redor de $10^{8} \mathrm{UFC} / \mathrm{mL}$.

É possivel elaborar a bebida láctea proposta analisando-se a aceitação pelos provadores e a viabilidade de Bif. longum e Lb. acidophilus após 21 de estocagem a $4^{\circ} \mathrm{C}$. 


\section{5 - REFERÊNCIAS BIBLIOGRÁFICAS}

[1] AOAC-Official Methods of Analysis of Association of Official Analytical Chemists. $16^{a}$ ed. Washington, v. $1-2,1995$.

[2] BOZANIC, R.; ROGELI, I.; TRATNIK, L.J. Fermented acidophilus goat's milk supplemented with inulin: comparison with cow's milk. Milchwissenchaft. v. 56, n. 11, p. 618-622, 2001.

[3] BRASIL, M. A. A. Padrões de Identidade e Gualidade de Leites Fermentados. Resolução $n^{\circ} 5$, de 13 de novembro de 2000. Publicada no Diário Oficial da União de 02 de janeiro de 2001, Seção I, págs 19 à 22. 2000.

[4] DAVE, R.I.; SHAH, N.P. Ingredient supplementation effects on viability of probiotic bacteria in yogurt. Journal of Dairy Science. v. 81, n.11, p. 2804-2816, 1998.

[5] DAVE, R.I.; SHAH, N.P. Evaluation of media for selective enumeration of Streptococcus thermophilus, Lactobacillus delbrueckii ssp bulgaricus, Lactobacillos acidophilus and bifidobacteria. Journal of Dairy Science. v. 79, n. 9, p. 1529-1536, 1996.

[6] DAVIDSON, R.H.; DUNCAN, S.E.; HACKNEY, C.R.; EIGEL, W.N.; BOLING, J.W. Probiotic culture survival and implications in fermented frozen yogurt characteristics. Journal of Dairy Science. v. 83, n. 4, p. 666-673, 2000.

[7] GOMES, A.M.P.; MALCATA, F.X. Bifidobacterium spp. and Lactobacillus acidophilus: biochemical, technological and therapeutical properties relevant for use as probiotics. Trends in Food Science and Technology. v. 10, n. 4/5, p. 139-157, 1999.

[8] KLAVER, F.A.M.; KINGMA, F.; WEERKAMP, A.H. Growth and survival of bifidobacteria in milk. Netherlands Milk Dairy Journal. v. 47, p. 151-164. 1993.

[9] LAPIERRE, L.; UNDELAND, P.; COX, L.J. Lithium chloride-sodium propionate agar for the enumeration of Bifidobacteria in fermented dairy products. Journal of Dairy Science. v. 75, n. 5, p. 1192-1196, 1992.

[10] LOURENS-HATTINGH, A.; VILJOEN, B.C. Yogurt as probiotic carrier food. International Dairy Journal. v. 11, n. 1, p. 1-17, 2001.

[11] LANKAPUTHRA, W.E.V.; SHAH, N.P.; BRITZ, M.L.. Survival of bifidobacteria during refrigerated storage in the presence of acid and hydrogen peroxide. Milchwissenchaft. v. 51, n. 2, p. 65-69. 1996

[12] MACFIE, H.J.; BRATCHELL, N.; GREENHOFF, K.; VALLIS, L.V. Designs to balance the effect of order presentation and first-order effects in hall tests. Journal of Sensory Studies. v. 4, n. 2, p. 129-148. 1989.

[13] MATTILA-SANDHOLM, T.; MYLLÄRINEN, P.; CRITTENDEN, R.; MOGENSEN, G.; FONDÉN, R.; SAARELA, M. Technological challenges or future probiotic foods. International Dairy Journal. v. 12, n. 2, p. 173-182, 2002.

[14] MATTILA-SANDHOLM, A.; MÄTTÖ, J.; SAARELA, M. Lactic acid bacteria with health claims - interactions and interference with gastrointestinal flora. International Dairy Journal. v. 11, n. 1, p. 1-17, 1999.
[15] MEIlGAARD, M.; CIVILlE, G.V.; CARR, B.T. Controls for tests room, product, and panel; Attribute difference tests: How does attribute $\mathrm{X}$ differ between samples; Affective tests: consumer tests and in-house panel acceptance tests; Basic statistical methods; Guidelines for choice of technique. In M. MEILGAARD, G.V. CIVILLE, B.T. CARR, Sensory evaluation techniques. London: CRC Press Inc, 1999. p. 23 36, 99 122, 231 304, 337344

[16] OLIVEIRA, M.N.; SODINI, I.; REMEUF, F.; TISSIER, J.P.; CORRIEU, G. Manufacture of fermented lactic beverages containing probiotic cultures. Journal of Food Science. v. 67, n. 6, p. 2336-2341, 2002.

[17] SAMONA, A.; ROBINSON, R.K.; MARAKIS, S. Acid production by bifidobacteria and yoghurt bacteria during fermentation and storage of milk. Food Microbiology. v. 13, n. 4, p. 275-280. 1996.

[18] SHAH, N.P.; LANKAPUTHRA, W.E.V.; BRITZ, M.L.; KYLE, W.S.A. Survival of Lactobacillus acidophilus and Bifidobacterium bifidum in commercial yoghurt during refrigerated storage. International Dairy Journal. v. 5, n. 5, p. 515-521. 1995.

[19] TAMIME, A.Y.; MARSHALL, V.M.E., ROBINSON, R.K. Microbiological and technological aspects of milks fermented by bifidobacteria. Journal of Dairy Research. v. 62, n. 1, p. 151-187, 1995.

[20] Vinderola, C.G.; PROSELlO, W.; GHIBERTO, D.; REINHEIMER, J.A. Viability of probiotic (Bifidobacterium, Lactobacillus acidophilus and Lactobacillus casei) and non probiotic microflora in Argentinian fresco cheese. Journal Dairy Science. v. 83, n. 9, p. 1905-1911, 2000a.

[21] VINDEROLA, C.G.; BAILO, N.; REINHEIMER, J.A. Survival of probiotic microflora in Argentinian yoghurts during refrigerated storage. Food Research International. v. 33, n. 2, p. 97-102. 2000b.

[22] VINDEROLA, C.G., REINHEIMER, J.A. Culture media for the enumeration of Bifidobacterium bifidum and Lactobacillus acidophilus in the presence of yoghurt bacteria. International Dairy Journal. v. 9, n. 8, p. 497-505. 1999.

[23] ZACARCHENCO, P.B.; MASSAGUER-ROIG, S. Enumeration of Streptococcus thermophilus in the presence of Bifidobacterium longum and Lactobacillus acidophilus - effect of incubation temperature and atmospheric conditions. Milchwissenchaft. v. 59, n. $7 / 8$, p. 370-372. 2004.

[24] Zacarchenco, P.B.; Massaguer-Roig, S. Differential enumeration of Bifidobacterium longum and Lactobacillus acidophilus in the presence of Streptococcus thermophilus. Milchwissenchaft. v. 59, n. 5/6, p. 258-261. 2004

[25] ZACARCHENCO, P.B. Leites fermentados por Str.thermophilus adicionados de $L b$. acidophilus e Bif.longum: Isolamento diferencial dos microrganismos, multiplicação em diferentes condições e efeitos nas características sensoriais dos leites fermentados naturais ou modificados. Campinas, 2004, 181p. Doutorado. Faculdade de Engenharia de Alimentos, Universidade Estadual de Campinas. 